\title{
SWIRLING FLOW IN FRANCIS TURBINES DEPENDING ON GUIDE VANES OPENING POSITION
}

\author{
Marina Cerpinska, Martins Irbe, Rihards Elmanis-Helmanis \\ Riga Technical University, Latvia \\ marina.cerpinska@rtu.lv, martins.irbe@ rtu.lv, rihards.elmanis-helmanis@ast.lv
}

\begin{abstract}
The objective of this paper is to discuss site tests, where the swirling flow and the resulting vortex rope were registered. The vortex rope is a low-frequency phenomenon occurring in the Francis turbine draft tubes. The draft tube surge (instability in the draft tube containing swirling flow) is flow-induced and results in vibration in hydroelectric machinery, which causes instability, restricts the operation of the turbine in specific modes and as a result does not allow to generate as much power as the user would like. The tests also showed that draft tube surge, if severe, could have effect on the generator. The selected data were obtained on the set of the Francis turbine hydropower units (98 MW rated output, $13.8 \mathrm{kV}, 50 \mathrm{~Hz}$ hydropower units with umbrella-type hydrogenerators) through many years of measurements in the Latvian hydro-electric power plant. The site tests showed that draft tube surge appeared at low generating power, as expected from the literature review, but this phenomenon was detected also quite close to the best efficiency point. The conditions necessary for the swirling flow to appear is not simply small generating power. It rather depends on the water head and the guide vanes opening position, which is adjustable in Francis turbines. For $98 \mathrm{MW}$ unit the swirling flow would appear at 60 MW power, but it could also appear at $80 \mathrm{MW}$ power at specific conditions presented in the paper.
\end{abstract}

Keywords: Francis, vortex rope, swirling flow.

\section{Introduction}

The review paper on the draft tube surge in Francis turbines [1] claims that respective phenomena have been researched for in the last three decades. In a Russian book it was mentioned in 1972 [2], so it has been almost 5 decades till now. The draft tube surge research problem was thoroughly addressed by EPFL, Lausanne, Russian Hydropower Institutes and the China Hydropower Institute, the Brno University of Technology, Kaplan Department of Fluid Engineering, the Czech Republic etc. The specific low frequency phenomena appeared in Latvian hydropower stations as well, but it was never reported before to the research community in details.

The goal of this paper is to summarise and compare the fundamental theoretical techniques of vortex rope prediction with the site tests results. Therefore, this paper aims to provide the summary on cases, when low frequency phenomena were registered in Latvia, as a humble contribution to the knowledge field on the topic.

The authors believe that every hydropower generation unit is unique, and this review of field studies and site investigations would be topical, although so many high-quality researches to examine the draft tube vortex phenomena have been done in the lab on reduced-scale models, stationary swirl generators and complete turbine models with a runner, where radial distribution of velocities are closer to that in an actual turbine [3] and through Computational Fluid Dynamics (CFD) simulations by other scholars. CFD simulations results have been presented since 1999 [3], but for this phenomenon computation simulation and field experiments are both important, because there are always small deviations in the turbine operation on site from that of the model predictions. As stated by Koutnik et.al., the vortex rope shape is hard to predict by CFD analyses [4]. It was fairly noted by Wang et.al. that not many researchers could take a large prototype of the Francis turbine as a research object by using ongoing site tests [5]. Site tests take years, if one would like to experiment with maximally different water head. Meanwhile, model tests do not show the full picture for special operating conditions [5] and "measured pressure pulsations cannot be directly transposed from model to prototype" [4].

In the Francis turbine the draft tube (composed of cone, elbow, and diffuser [6]) is responsible for waste water to flow into the downstream reservoir. There is always a little swirl entering the draft tube [3], because water enters the Francis turbine radially - from the river side, but exits down at some angle (axially), and water keeps some radial momentum. At the best efficiency discharge the swirl is almost zero, therefore called "zero swirl [3]". In contrary, for some operation modes the swirl gets larger, causes vibration and requires user attention. Since Nishi research in 1980 [7], the research community agrees that "the pulsation consists of a synchronous part, a plane wave, and an 
asynchronous part - the precession movement of the rope" [3]. The authors developed the theoretical equations to describe the phenomena in [8].

Majority of authors agree that swirling flow occurs far from the best efficiency [9] at both high and low load [3;10], and for overload as well [11], and experts point out that swirling flow is characteristic specifically to the low load at $60-65 \%$ from unit optimal power [11].

The hydropower turbines are slow-speed machines. Most of the units have the speed in the range $1-3 \mathrm{~Hz}$ [11]. The researched units have the rotational speed $1.47 \mathrm{~Hz}$. Meantime, draft tube surge is even more typical for partial load cases, and its frequency is a couple times smaller than the rotational frequency and it is not constant in different modes [11]. A number of vortex rope frequency prediction techniques are available in the literature [1]. The authors mainly try to give one coefficient, which would be useful for the design stage. As noted by Wang: "The characteristic frequency of unsteady hydraulic feature is not clear until now for such a large turbine at different operation conditions" [5]. As early as in 1940 Rheingans quoted in [1] found out the dominant frequency "being close to 1/3.6 times the runner rotational speed at the greatest pressure fluctuations". In a Russian book the coefficient of 4.2-4.6 was proposed for Kaplan turbines [2;11], but for Francis turbines the coefficient 3.6 remains true in the performed site tests.

The fact that swirling flow has low frequency (even as low as $1 \mathrm{~Hz}$ ) brings some consequences.

As noted by [3], the swirling flow frequency could be close to $1 \mathrm{~Hz}$, and therefore it can produce output power swings $[3 ; 10 ; 12 ; 13]$.

User should use special equipment to register swirling flow vibration, because accelerometers are rarely designed to register such low frequencies, therefore, for the site tests displacement sensors were chosen as described further in the Materials and methods section. Displacement of the shaft shows well the changes in vibration under $1 \mathrm{~Hz}$ during slow-speed motion.

Finally, let us discuss the most efficient ways of elimination of the vortex rope. Over two decades users deal with the draft tube surge problem by air injection and installation of fins [8]. However, injection of compressed air into the draft tube requires considerable power [7]. In Latvia the fins (locally called the ribs) were installed on one of the hydropower units, and the researcher, who participated in the design and installation process, claimed that it was a successful solution, which reduced low frequency vibration on part load and reduced vibration in general as well [14], but for this paper we purposely chose the units where no fins were installed. As stated by [3], sometimes neither air injection nor fins installation solve the problem, and the user still needs to adjust operation of the turbine to avoid vibration caused by vortex rope.

\section{Materials and methods}

The data presented in this paper were selected from structural vibration measurements. It was specifically radial and vertical displacement of four hydropower turbines of the Francis type, called in the paper F1, F2, F3, F4. The rated speed of the units was 88.2 RPM. Selected units have 98 MW rated power. The units were first put in operation in 1965, two units were modernized ten years ago. Compared to other studies like [5], the investigation was carried for a rather narrow load range of 60 MW-103 MW in the condition of the water head $34 \mathrm{~m}-39 \mathrm{~m}$, and it still took around five years to complete. Although it is known that vortex rope appears "over a range of the relative turbine discharge between approximately 0.5 and 0.85 of the flow at best efficiency" [3], on site turbine discharge is hard to measure, and we prefer to measure some relative parameters, like the velocity of the flow or the pressure in the water channels. In this paper we would concentrate on the parameters, which are easy to measure and control - water head, guide vanes opening position and generated power.

The directions, in which the user would like to register displacement to get the full picture of the vortex rope effects, are radial and vertical directions.

- Radially. Shaft displacement relative to the thrust bearing case. In radial direction one would register effects of vortex rope, which dissolves at the top of the draft tube [11]. For shaft displacement, two non-contact inductive probes were displaced by 90 degrees on both the generator and turbine bearings to measure the radial relative displacement.

- Vertically. Turbine vertical displacement relative to the turbine casing wall. In vertical direction the user could register greater displacement, when vortex rope dissolves at the 
bottom of the draft tube [11]. For some measurements a special rod was added to the turbine wall and an inductive probe attached to this rod to register displacement in vertical direction.

The sensors chosen were inductive displacement sensors of type CMSS68 with sensitivity of $7.8 \mathrm{mV} / \mu \mathrm{m}$, displacement range $0-2,7 \mathrm{~mm}$. The 3 minutes long signal obtained in each mode was analysed to ensure statistically correct data. The multi-channel FFT analysis of data was made through National Instruments LabVIEW software. For spectrum results FFT was used. In this paper the obtained results were exported to MSC Excel. All presented values are RMS values.

\section{Results and discussion}

Vortex rope characteristic frequency amplitude could be greater than nominal rotational speed characteristic frequency amplitude.

As early as in 1972 [2] it was noted that draft tube surge does not depend only on the rotating speed of the turbine, but rather on its load. Both part load and overload instabilities depend on the net head of the machine [12]. In Fig. 1 the spectrum of the shaft displacement relative to the turbine bearing for unit F1 is presented, when the net head was low, and the net load was small.

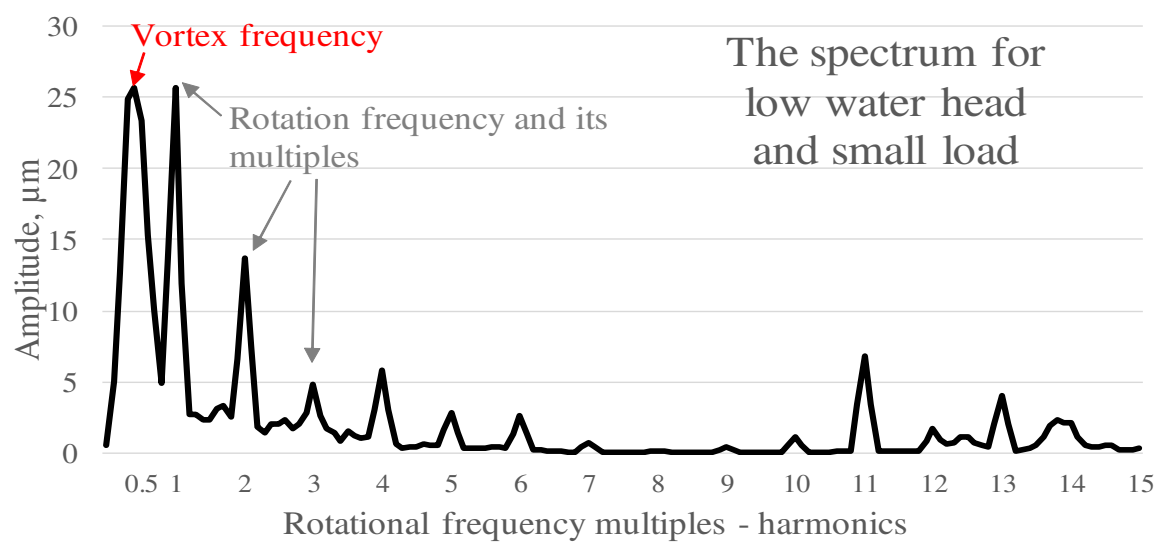

Fig. 1. Shaft displacement relative to turbine bearing of $\mathrm{F} 1$ at $65 \mathrm{MW}, 34.03 \mathrm{~m}$ head

In Fig. 1 the harmonic of the draft tube surge is $0.3 \mathrm{X}-0.5 \mathrm{X}$. It is the vortex rope characteristic frequency [1]. It has greater amplitude than harmonic $1 \mathrm{X}$ for nominal rotational speed. The nominal rotational speed frequency $1 \mathrm{X}$ is almost always dominant in the vibration spectrum, therefore, this case is of special interest to diagnosticians. The water head was very low, just $34.03 \mathrm{~m}$, and the guide vanes opening position was small $355 \mathrm{~mm}$, so the load was minimal - $65 \mathrm{MW}$. This example supports the statement that draft tube surge appears on low load, because the turbine was operated at $65-66 \mathrm{MW}$ out of $98 \mathrm{MW}$, while the maximum load registered at $34.03 \mathrm{~m}$, the head was $88 \mathrm{MW}$.

The situation, when the vortex frequency was greater than the rotational frequency, was registered for another unit as well. In the year of 2015 the unit F2 was tested for the load from around $58 \mathrm{MW}$ to $98 \mathrm{MW}, 0 \mathrm{MVAr}$, at the water head $37 \mathrm{~m}$, the suction head was $2.84 \mathrm{~m}$. In Table 1 the data, where vortex rope was detected and was greater than the rotational frequency, are presented. For greater power vortex registered, the amplitude was small $-3 \mu \mathrm{m}$ and $4 \mu \mathrm{m}$.

Table 1

Vortex rope amplitude greater than main frequency, unit F2, $37 \mathrm{~m}$ head

\begin{tabular}{|c|c|c|c|c|c|c|c|}
\hline \multirow{3}{*}{$\begin{array}{l}\text { Power, } \\
\text { MW }\end{array}$} & \multirow{3}{*}{$\begin{array}{l}\text { Guide vanes } \\
\text { opening } \\
\text { position, } \mathbf{m m}\end{array}$} & \multicolumn{4}{|c|}{ Radial shaft displacement, $\mu \mathrm{m}$} & \multirow{2}{*}{\multicolumn{2}{|c|}{$\begin{array}{c}\text { Vertical } \\
\text { displacement, } \mu \mathrm{m}\end{array}$}} \\
\hline & & \multicolumn{2}{|c|}{ Sensor 1} & \multicolumn{2}{|c|}{ Sensor 2} & & \\
\hline & & Vortex freq. & 1X & Vortex freq. & 1X & Vortex freq. & $1 \mathrm{X}$ \\
\hline 58.8 & 317 & 71 & 17 & 52 & 16 & 54 & 18 \\
\hline 62.9 & 330 & 46 & 19 & 32 & 21 & 43 & 19 \\
\hline 66.5 & 340 & 21 & 7 & 16 & 6 & 23 & 15 \\
\hline 69.5 & 351 & 19 & 6 & 16 & 4 & 21 & 16 \\
\hline 73.7 & 362 & 11 & 6 & 8 & 5 & 15 & 17 \\
\hline 75.7 & 371 & 7 & 7 & 5 & 4 & 12 & 16 \\
\hline
\end{tabular}


Table 1 confirms that vortex rope is indeed the greatest for a small load as $58.8 \mathrm{MW}$, but it is still present for a medium load 75.7 MW for this unit. The same unit was tested in 2015 for the water head $38 \mathrm{~m}$, the suction head was $4.46 \mathrm{~m}$. Table 2 shows that the draft tube surge was less severe for this head.

Table 2

Vortex rope amplitude greater than main frequency, unit F2, $38 \mathrm{~m}$ head

\begin{tabular}{|c|c|c|c|c|c|c|c|}
\hline \multirow{3}{*}{$\begin{array}{c}\text { Power, } \\
\text { MW }\end{array}$} & \multirow{3}{*}{$\begin{array}{c}\text { Guide vanes } \\
\text { opening } \\
\text { position, mm }\end{array}$} & \multicolumn{4}{|c|}{ Radial shaft displacement in $\mu \mathrm{m}$} & \multirow{2}{*}{\multicolumn{2}{|c|}{$\begin{array}{c}\text { Vertical } \\
\text { displacement in } \\
\mu \mathrm{m}\end{array}$}} \\
\hline & & \multicolumn{2}{|c|}{ Sensor 1} & \multicolumn{2}{|c|}{ Sensor 2} & & \\
\hline & & Vortex freq. & $\mathbf{1 X}$ & Vortex freq. & $\mathbf{1 X}$ & $\begin{array}{l}\text { Vortex } \\
\text { frea. }\end{array}$ & $\mathbf{1 X}$ \\
\hline 63.03 & 317 & 14 & 6 & 10 & 5 & 10 & 5 \\
\hline 68.50 & 335 & 11 & 6 & 7 & 5 & 10 & 5 \\
\hline 72.68 & 349 & 8 & 7 & 5 & 6 & 14 & 5 \\
\hline 77.81 & 361 & 11 & 7 & 6 & 6 & 10 & 6 \\
\hline 81.15 & 370 & 8 & 7 & 4 & 5 & 11 & 5 \\
\hline 84.2 & 379 & 5 & 8 & 3 & 6 & 7 & 5 \\
\hline
\end{tabular}

Comparing Table 1 and Table 2, it may seem that the lower the water head, the greater the vibration caused by vortex rope should be. It is only partly true. In 2015 the unit F2 was tested at the lowest possible water head $34.8 \mathrm{~m}$, the suction head was $1.61 \mathrm{~m}$. For vertical displacement the vortex frequency was noticeable, but not higher than $1 \mathrm{X}$ for loads $68 \mathrm{MW}, 71 \mathrm{MW}, 73.6 \mathrm{MW}$, meanwhile radial displacement did not show significant effect of the vortex rope, it was not higher than $1 \mathrm{X}$, for $68 \mathrm{MW}$ it was the same $-9 \mu \mathrm{m}$ and in the rest of the modes it was smaller.

Upgraded units experience vortex caused vibration mainly in vertical direction at low load.

Units F3 and F4 were upgraded one decade ago. Unit F3 was tested in 2015 at the water head of $35.48 \mathrm{~m}$, the suction head was $2.35 \mathrm{~m}$, for the power range from $71.6 \mathrm{MW}$ to $92.8 \mathrm{MW}$. Vortex caused vibration was detected through vertical displacement in modes under $80 \mathrm{MW}$, radial displacement showed only values less than $5 \mu \mathrm{m}$. Another two tests were performed in 2015 at a similar water head of $34.86 \mathrm{~m}$, the suction head was first $0.54 \mathrm{~m}$, the power range achieved was 66.2-92 MW and then the suction head was $1.72 \mathrm{~m}$, and the power range achieved was 65.3-90.8 MW. Vertical displacement amplitude of vortex rope was greater than $5 \mu \mathrm{m}$ under $75 \mathrm{MW}$, reaching $30 \mu \mathrm{m}$ at $66 \mathrm{MW}$ and 65 MW, while radial displacement amplitude of vortex rope was never greater than $1 \mathrm{X}$, reaching maximum of $20 \mu \mathrm{m}$ at $66 \mathrm{MW}$ and $15 \mu \mathrm{m}$ at $65.3 \mathrm{MW}$, less than $10 \mu \mathrm{m}$ at under $70 \mathrm{MW}$, and less than $5 \mu \mathrm{m}$ at other modes.

Unit F4 was tested in 2015 at the water head $34.36 \mathrm{~m}$, the suction head was $1.59 \mathrm{~m}$, the power range from 66.5 MW to $91.4 \mathrm{MW}$, and vortex vibration was detected through vertical displacement and radial displacement. It was over $10 \mu \mathrm{m}$ for small loads under $75 \mathrm{MW}$ only and was never greater than 1X. Specifically, the vertical vortex caused vibration frequency was $18 \mu \mathrm{m}$ (while $1 \mathrm{X}$ was $21 \mu \mathrm{m})$ at $66.5 \mathrm{MW}, 12 \mu \mathrm{m}(1 \mathrm{X}$ was $21 \mu \mathrm{m})$ at $69.7 \mathrm{MW}$, and for the rest of the modes less than $10 \mu \mathrm{m}$. Meanwhile, radial displacement showed vortex vibration values greater than $10 \mu \mathrm{m}$ only in 66.5 MW mode $-19 \mu \mathrm{m}(1 \mathrm{X}$ was $63 \mu \mathrm{m})$ and $18 \mu \mathrm{m}(1 \mathrm{X}$ was $64 \mu \mathrm{m})$. However, at the water head $36.85 \mathrm{~m}$ (Hs was 2.67) at low load of 64.1 MW vortex effect on vertical vibration was greater $-29 \mu \mathrm{m}$ (1X was $20 \mu \mathrm{m}$ ). For radial displacement it was $25 \mu \mathrm{m}$, although $1 \mathrm{X}$ was greater $-62 \mu \mathrm{m}$.

Vortex rope caused vibration appears at low load and at medium load of $80 \mathrm{MW}$.

Another set of tests for unit F4 was run in 2015 at the water head of $37.57 \mathrm{~m}$, the suction head $4.19 \mathrm{~m}$ and the water head $38.6 \mathrm{~m}$, the suction head $4.28 \mathrm{~m}$. At the water head $37.57 \mathrm{~m}$ vortex rope caused vibration reached maximum at power less than $76 \mathrm{MW}$, when the guide vanes opening position (GVOP) was less than $351 \mathrm{~mm}$. At the water head of $38.6 \mathrm{~m}$ under power of $84 \mathrm{MW}$ it was $10 \mu \mathrm{m}$ (1X was $21 \mu \mathrm{m}$ ). For unit F4 power as high as $103.7 \mathrm{MW}$ was reached at the water head $38.6 \mathrm{~m}$, and for the power over $100 \mathrm{MW}$ the vortex rope frequency through vertical displacement increased steadily, reaching $9 \mu \mathrm{m}$ at $103.7 \mathrm{MW}$ and $475 \mathrm{~mm}$ GVOP. To sum up, the statement that Francis turbines operate poorly at part loads, which means "low flow rates with small guide vane opening angles" [5] 
(for our units that was 60-70 MW) remains true even for upgraded units, and it is possible to detect vortex frequency close to $80 \mathrm{MW}$.

Draft tube surge appears at small guide vanes opening position.

Control over the river head is very limited. Meanwhile, in the Francis turbine the user can change the guide vanes opening position to achieve the desired load at the given head. For example, on unit F1 to obtain $80.64 \mathrm{MW}$ at $38.8 \mathrm{~m}$ head, the guide vanes opening should be $349 \mathrm{~mm}$; to obtain $82.48 \mathrm{MW}$ at $37.8 \mathrm{~m}$ head, the guide vanes opening should be $365 \mathrm{~mm}$; to obtain $81.87 \mathrm{MW}$ at $37 \mathrm{~m}$ head, the guide vanes opening should be $376 \mathrm{~mm}$, at $34 \mathrm{~m}$ head to obtain $80.7 \mathrm{MW}$ the guide vanes opening should be as great as $406 \mathrm{~mm}$. To sum up, the smallest is the water head at the given date, the greater the guide vane opening should be to achieve the same desired power. Fig. 2 hows the data from one displacement sensor, when the load was close to $80 \mathrm{MW}$, but the water head and the guide opening position were different. In this example $34 \mathrm{~m}$ water head is low. GVOP of $406 \mathrm{~mm}$ is large. Since the measurements were made on different dates, the data are organised as overlapping spectral lines instead of the waterfall chart.

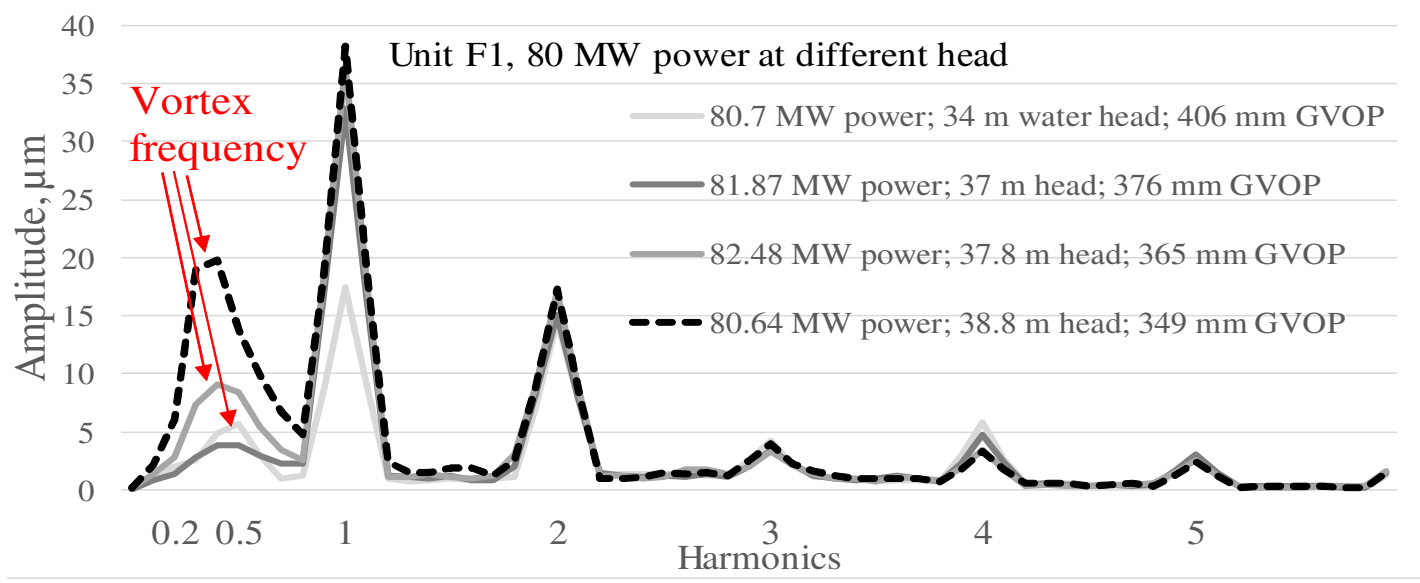

Fig. 2. Comparison of spectrum lines for unit F1 at load close to 80 MW

Vortex rope caused vibration was registered in all modes for this unit, but its amplitude was different. Opposite to expectations that amplitude would be the greatest at a low head of $34 \mathrm{~m}$, indicated by the lightest grey line in Fig. 2, it was greater at $38.8 \mathrm{~m}$ water head, indicated by the dotted line in Fig. 2. Contrary to the expectation that vortex rope would appear when the guide vane opening position is large and the water head is small, it was greater, when the water head was high and GVOP was small.

\section{Draft tube surge has effect on the generator.}

Normally the user would register draft tube surge only at the turbine bearing and only in very severe cases on the generator bearing. Table 3 shows that rarely, but on specifically unfavourable modes, the user would note the vortex typical vibration not only from the turbine bearing shaft displacement sensor, but also from the generator bearing shaft displacement sensors.

Table 3

Different measurement positions - registered vortex rope $(<1 \mathrm{X})$ in $\mu \mathrm{m}$

\begin{tabular}{|c|c|c|c|c|c|}
\hline GVOP/Sensor & Turbine 1 $^{\text {st }}$ & Turbine 2nd & Generator 1st & Generator 2nd & Vertical \\
\hline 355 & 24 & 26 & 6 & 9 & 24 \\
\hline 370 & 11 & 10 & 2 & 3 & 13 \\
\hline 386 & 3 & 3 & - & - & 5 \\
\hline 397 & 4 & 3 & - & - & - \\
\hline 406 & 6 & 6 & - & - & - \\
\hline $416-474$ & $5-6$ & $4-5$ & - & - & $1-4$ \\
\hline
\end{tabular}

In Table 3 the dash means that vibration was less than $2 \mu \mathrm{m}$. The values in the first two rows of Table 3 confirm that draft tube surge, if severe, has effect on the generator vibration. 


\section{Conclusions}

1. This paper showed appreciation to the fact that every hydropower unit is unique, and site tests are necessary to learn every unit behaviour in different conditions. There are though commonalities in operation. All Francis turbines operated with draft tube surge at part load (in this paper it was 60$70 \mathrm{MW}$ out of maximum $98 \mathrm{MW}$ ), far from the best efficiency point.

2. Although all hydropower turbines including upgraded units experienced effects of draft tube surge at low load, there were other specific findings during the tests:

- For unit F1, F2 and F4 it was possible to detect the vortex rope frequency close to optimum at $80 \mathrm{MW}$.

- For unit F1 the vortex rope frequency was greater, when the water head was high and GVOP was small.

3. The site tests confirmed that draft tube surge, if severe, could have effect on the hydropower unit generator vibration.

\section{References}

[1] Nishi M., Liu S. An Outlook on the Draft-Tube-Surge Study. Review Paper (Invited). International Journal of Fluid Machinery and Systems, vol. 6, No. 1, 2013, pp. 33-48.

[2] Владиславлев Л.А. Вибрация гидроэлектрических станций (Vibration of hydroelectric power plants). М., Энергия, 1972. (In Russian).

[3] Dörfler P., Sick M., Coutu A. Flow-Induced Pulsation and Vibration in Hydroelectric Machinery. Springer-Verlag London, 2013. DOI: 10.1007/978-1-4471-4252-2_2

[4] Koutnik J., Krüger K., Pochyly F., Rudolf P., Haban V. On cavitating vortex rope form stability during Francis turbine part load operation. IAHR Int. Meeting of WG on Cavitation and Dynamic Problems in Hydraulic Machinery and Systems, June 28-30, 2006, Barcelona, Spain, pp. 1-10.

[5] Wang F., Li X., Ma J., Yang M. Experimental investigation of characteristic frequency in unsteady hydraulic behaviour of a large hydraulic turbine. Journal of Hydrodynamics, vol. 21(1):12-19, 2009, pp.12-19. DOI: 10.1016/S1001-6058(08)60113-4

[6] Iliescu M. S., Ciocan G. D., Avellan F. Analysis of the cavitating draft tube vortex in a Francis turbine using particle image velocimetry measurements in two-phase flow. Journal of Fluids Engineering, vol. 130.2, 2008, pp. 021105-1-021105-10. DOI: 10.1115/1.2813052

[7] Nishi M., Kubota T., Matsunaga S., Senoo Y. Study on swirl flow and surge in an elbow type draft tube. In Proceedings of "10th IAHR Symposium on Hydraulic Machinery and Cavitation", vol. 1, 1980, Tokyo, Japan, pp. 557-568.

[8] Nishi M., Wang X.M., Yoshida K., Takahashi T., Tsukamoto T., An experimental study on fins, their role in control of the draft tube surging. Proceedings of the "XVIII IAHR Symposium on Hydraulic Machinery and Cavitation”, 1996, pp. 905-914.

[9] Susan-Resiga R. F., Muntean S., Tanasa C., Bosioc A. Three-dimensional versus two-dimensional axisymmetric analysis for decelerated swirling flows. Proceedings of the "13th International Conference on Fluid Flow", September 6-9, 2009, Budapest, Hungary, pp. 1-7.

[10] Wu Y., Li S., Liu S., Dou H. S., Qian Z. Vibration of hydraulic machinery. Netherlands: Springer, 2013. $500 \mathrm{p}$.

[11]Иванченко И.П., Прокопенко А.Н. Вибрационная диагностика гидротурбин (Vibration diagnostics of hydropower turbines). В кн. Диагностика турбинного оборудования электрических станций. Saint Petersburg: ПЭИПК, 2004, pp. 223-262. (In Russian).

[12] Valentin D., Presas A., Egusquiza E., Valero C., Egusquiza M., Bossio M. Power swing generated in Francis turbines by part load and overload instabilities. Energies, vol. 10, 2124, 2017, pp. 1-17. DOI:10.3390/en10122124

[13]Zuo Z., Liu S., Liu D., Qin D. Numerical predictions and stability analysis of cavitating draft tube vortices at high head in a model Francis turbine. Science China, Technological Sciences, vol. 57(11), 2014, pp. 2106-2114. DOI: 10.1007/s11431-014-5618-x

[14]Прокопенко А. Н. Расчетно-экспериментальное обоснование зависимости вибрационных характеристик гидроагрегатов от конструктивных и режимных факторов. (Numerical and experimental verification on dependency of hydropower units' vibration from design factors and operational modes specifics), Doctoral dissertation, Saint Petersburg: СПГПУ, 2014, pp. 221. (In Russian). 